\title{
The causal effect of the great recession on childlessness of white American women
}

\author{
Chiara Ludovica Comolli ${ }^{*}$ [D and Fabrizio Bernardi
}

\author{
* Correspondence: \\ chiara.comolli@eui.eu \\ European University Institute, \\ Firenze, Italy
}

\begin{abstract}
Many studies have documented a negative association between macroeconomic indicators and fertility in times of economic crisis. These studies are based on research designs that do not allow for excluding that the observed association is driven by confounders. The aim of the present paper is to estimate the causal effect of the Great Recession on cohorts' childlessness in the United States. We apply a difference-in-difference approach to the probability of childlessness in two pseudo-cohorts of white women who entered the age of 34-36 years old being childless before the crisis, in 2004, and at the onset of the crisis, in 2007. Our identification strategy relies on the assumption that these two adjacent cohorts of women differ only because the latter cohort lived some critical years of reproductive life during the Great Recession period. We then study how many childless women aged 34-36 had a child when they were 37-39, between the years 2004 and 2007 for the control group and between the years 2007 and 2010 for the treatment group. We argue that an increase of childlessness at the age 37-39 is likely to lead to an increase in permanent childlessness, since major catch-up processes are unlikely after age 40 . We replicate the analysis on two datasets: the American Community Survey and the Fertility Supplement of the Current Population Survey. Our findings suggest that the Great Recession has had a positive, though mild, effect on childlessness of white women at about the age of 40 in the US.
\end{abstract}

JEL codes: Z0, J1, J110, J130, C21*

Keywords: Fertility, Great recession, United States, Difference in difference, Childlessness

\section{Introduction}

Economic and labor market uncertainties are important determinants of the postponement of childbearing in contemporary society (Goldstein et al. 2013; Kreyenfeld and Andersson 2014; Sobotka et al. 2010, 2011). Empirical evidence also supports a historical pro-cyclical relationship between fertility rates and business cycle fluctuations (Silver 1965; Lee 1990; Sobotka et al. 2011). At the aggregate level this holds true for the majority of the $20^{\text {th }}$ century financial and economic crises that, albeit very differently, brought about a more or less pronounced reduction of birth rates (Sobotka et al. 2010, 2011).

The decline in fertility, though, is usually rather small and temporary because socioeconomic factors are relatively short-term events compared to secular demographic patterns (Lesthaeghe 2010). All the $20^{\text {th }}$ century crises occurred in a context of a long- 
term fertility decline that was only accelerated by economic downturns (Morgan et al. 2011, 2012; Sobotka et al. 2010, 2011).

Despite being of small magnitude and mostly entailing only a postponement of births, the negative effect of economic hardship on fertility is an established finding in the literature: Sobotka et al. $(2010,2011)$ show that, among 27 low-fertility countries in the period 1980-2008, GDP decline is associated with a drop in fertility $81 \%$ of the times. Morgan et al. (2011) find the same result in the US: when the economy plunges, so does fertility. Already G.S. Becker (1960) argued that changes in fertility rates were positively correlated with the purchase of durable goods, and more recent studies observe a positive relationship between consumer confidence and fertility (Fokkema et al. 2008; Giersbergen and de Beer 1997).

In addition, a negative association between unemployment rates and fertility rates has been assessed in both the US (Currie and Schwandt 2014; Adsera 2004; Dehejia and Lleras-Muney 2004; Macunovich 1996; Rindfuss, Morgan, and Swicegood 1988) and in Europe (Inanc 2015; Del Bono et al. 2014; Kreyenfeld and Andersson 2014; Adsera 2011; Sobotka et al. 2010, 2011; Meron and Widmer 2002; Ermisch 1988a).

In contrast, very few studies (Butz and Ward 1979; Ermisch 1980, 1988b) put forward the theory that women take advantage of the limited opportunities in the labor market during recessions to have children. In a well known, but questioned (Ahlburg 1983; Macunovich 1995, 1996; McDonald 2000) study, Butz and Ward (1979) argued that fertility becomes counter-cyclical with women's rising employment rates because of the lower opportunity cost of childbearing.

With few exceptions (Del Bono, Weber, and Winter-Ebmer 2014; Dehejia and LlerasMuney 2004; McKenzie 2003), however, most of these studies are based on associational evidence of macro economic indicators to fertility, and it is hard to interpret the observed relationship as causal.

In this paper we move forward the debate on the consequences of business cycles fluctuations for fertility, and in particular, we make two contributions to the existing literature. First, we focus on the effect of the Great Recession on the childbearing behavior of childless women at age 34-36 at the beginning of the economic crisis in 2007. Previous studies have shown that economic downturns are typically associated to a postponement of fertility, but a postponement of the first child for these women is critical because after 40 it becomes increasingly difficult to conceive. By focusing on this specific age group, we can then approximate the effect of Great Recession on permanent childlessness, at least for a given cohort of white American women born between 1971 and 1973.

Second, we present an identification strategy that can be profitably applied to investigate the causal effect of the Great Recession (or of any other aggregate shock or period effect) in other countries and to other outcomes. The identification of any causal effect deriving from the Great Recession is complicated because it is extremely hard to find an appropriate control group. The economic and financial crisis spread all over developed countries, within the US in every state, and-though with different intensityaffected all socio-demographic groups, which makes it arduous to find two comparable groups of individuals, one hit by the crisis while the other is not. The solution we adopted in this study is to compare the probability of childlessness before and after the recession in similar groups of women, not across space, but across time, combining the 
difference-in-difference (DD) method with the pseudo-cohort approach (Deaton 1985; Moffitt 1993; Collado 1997; McKenzie 2004; Verbeek and Vella 2005; Verbeek 2008). More precisely, we apply a DD approach to the probability of childlessness in two pseudo-cohorts of women: those who entered the age of 34-36 years old being childless before the crisis, in 2004, and those turning 34-36 and being childless in 2007 at the onset of the crisis. ${ }^{1}$ We then study how many of these childless women had a child by the age of 37-39, i.e., between the years 2004 and 2007 for the control group and between the years 2007 and 2010 for treatment group. Our identification strategy relies on the assumption that these two adjacent cohorts of women differ only because the latter cohort lived some critical years for the reproductive life, those between age 34 and 39, during the Great Recession period. Pre-treatment differences in fertility trends in the two cohorts can be taken into account using a DD design. ${ }^{2}$

To test the robustness of our findings, we conduct identical analyses on two US Census datasets: the American Community Survey (ACS) and the Fertility Supplement of the Current Population Survey (June CPS). Internal replication is still rare in the social sciences literature; nonetheless, it is a fundamental tool to substantiate findings and validate results with repeated trials. Internal replication is especially useful in the case of large datasets, like the ones we use in this paper, where sampling error-the only source of uncertainty that confidence intervals engage with-is less worrisome compared to other sources of uncertainty deriving from the data collection process (Firebaugh, 2008). In our specific case the source of uncertainty we address is measurement error in the dependent variable, childlessness, which is measured with some noise in the ACS sample. Finding analogous results in the two surveys would suggest that our estimate of the effect of the Great Recession on childlessness is not an artifact of specific survey attributes. As complementary analyses, we have also applied the same DD design to different age groups and used a different identification scheme studying the effect of unemployment rates on childlessness rates of 37 to 39-year-old women in the last twelve years, controlling for state and year fixed effects. ${ }^{3}$

The paper is organized as follows: in section 2 we describe the identification strategy, and we illustrate the few previous applications of this strategy in population studies; in section 3 we discuss the choice of our dependent variable, childlessness, and the datasets we use. In section 4 we present the main findings, and in section 5 the results of the complementary analyses. In the conclusions we discuss some of the potential mechanisms driving the results and briefly highlight the socioeconomic implications of rising childlessness. Finally, we suggest some possible applications of the "treatment at specific age with pseudo cohorts" design presented in this paper to other demographic outcomes and to other treatments beyond the Great Recession.

\section{Identification strategy}

When estimating the effect of an economic crisis on fertility behavior, a major concern is that unobserved heterogeneity might bias the estimate of the true causal effect, at least as long as there is a correlation in those characteristics of the groups between the treatment and the outcome under study. Being that these group traits are unobserved, it is unlikely that researchers can actually address this endogeneity by simply adding further covariates in the traditional regression framework. Moreover, the identification of any causal effect of the Great Recession is complicated by the difficulty in finding an 
appropriate control group. ${ }^{4}$ It is extremely hard, in fact, to find a control group that has not been hit by the crisis but is comparable to the treatment group in all other characteristics, observable and unobservable. The solution adopted in this paper is to compare groups of women, not across space, as usually done, but across time, identifying the causal effect of the Great Recession on childlessness via a DD approach applied to pseudo-panels of American white women. Specifically, our treatment and control groups of women differ with regard to the time period in which they turn a specific age. We focus on childless women in their late thirties and differentiate between the treated women, who spent some crucial years of their reproductive life during the Great Recession, and the control women who spent the same years just before the onset of the crisis. This design can be described as 'treatment at a specific age with pseudo cohorts, ${ }^{5}$ and it can be applied to estimate the postponement effect of the recession on fertility at any age. We focus, however, on women close to the end of their reproductive life for whom postponing their first birth likely means renouncing motherhood. We define as crucial years for women's fertility the age range between 34 and 39 years old because a postponement of childbearing at that age is more likely to slide into a reduction in completed fertility (Mynarska et al. 2015).

Equation 1 illustrates that the DD causal estimate is, in fact, a difference between two differences. $\mathrm{Y}$ is the proportion of childless women. The upper numbers 0 and 1 refer respectively to age 34-36 and age 37-39, while the lower letters $\mathrm{T}$ and $\mathrm{C}$ refer to the treatment and control group. The control group is given by childless women who turned 34-36 in 2004, while the treatment group consists of the childless women who turned 34-36 in 2007. The resulting effect $\left(\hat{\delta}_{D D}\right)$ is entirely attributed to the treatment and in our case expresses the causal estimate of the average treatment effect of the Great Recession on childlessness rates of women close to their forties.

$$
\hat{\delta}_{D D}=\left(Y_{T}^{1}-Y_{T}^{0}\right)-\left(Y_{C}^{1}-Y_{C}^{0}\right)
$$

For this effect to be identified, the DD method relies on the parallel trend assumption: in the absence of the treatment, the outcome paths of the two groups should not be systematically different. In more formal terms, we are assuming the additive structure of the potential outcomes in the no-treatment state. This means that in the absence of the Great Recession (treatment) the rate of childlessness is determined by the sum of a fixed, time constant, group-specific effect and a time-specific effect common to both groups. This is essential in DD since, in practice, the pre-treatment trend is extrapolated into the post-treatment period as a counterfactual.

The second component of our identification strategy is the concept of pseudo (or synthetic) panels (Deaton 1985). Pseudo-panel data are pooled cross-sectional data collected over time. ${ }^{6}$ They differ from true panel data, where information is collected repeatedly from the same individuals across waves, because what is repeatedly collected from cross-sectional data are random samples of individuals drawn from the same time-stable cohort. In this way it is as if we were aggregately following the same group of individuals over time without having real longitudinal data. We thus apply DD to pseudo-cohorts of white American women.

Consider Fig. 1, which illustrates the pseudo-panel schema and the cohorts selected. White Caucasian non institutionalized ${ }^{7}$ women are grouped according to their year of 


\begin{tabular}{|c|c|c|c|c|c|c|c|c|c|c|c|}
\hline Birth Cohort & 2001 & 2002 & 2003 & 2004 & 2005 & 2006 & 2007 & 2008 & 2009 & 2010 & Group \\
\hline 1965 & 36 & 37 & 38 & 39 & & & & & & & \multirow{3}{*}{$\mathbf{P}$} \\
\hline 1966 & 35 & 36 & 37 & 38 & & & & & & & \\
\hline 1967 & 34 & 35 & 36 & 37 & & & & & & & \\
\hline 1968 & & & & 36 & 37 & 38 & 39 & & & & \multirow{3}{*}{ C } \\
\hline 1969 & & & & 35 & 36 & 37 & 38 & & & & \\
\hline 1970 & & & & 34 & 35 & 36 & 37 & & & & \\
\hline 1971 & & & & & & & 36 & 37 & 38 & 39 & \multirow{3}{*}{$\mathbf{T}$} \\
\hline 1972 & & & & & & & 35 & 36 & 37 & 38 & \\
\hline 1973 & & & & & & & 34 & 35 & 36 & 37 & \\
\hline
\end{tabular}

Fig. 1 Pseudo-Panel schema

birth so that treatment and control groups of women differ with regard to the time period at which they turn a specific age. Women in the treatment group (T) are born between 1971 and 1973; thus, they turn 34-36 years old in 2007, and they spend the years close to the end of their reproductive life during the Great Recession, which bursts in December 2007. ${ }^{8}$ Women belonging to the $1968-70$ pseudo-cohort form instead our control group $(C)$ : they are 34-36 in 2004, meaning that they spend the same period close to the end of their reproductive life just before the onset of the crisis. ${ }^{9}$ Childlessness is measured for both groups when they are 37-39 years old, as the probability of a woman of a specific cohort of being childless in a given year.

Within the regression framework, the model is illustrated in Eq. 2. The variable Age37-39 is a dummy for being 37-39, which refers to the year 2010 for the treatment group and for the year 2007 for the control group. The variable Treatment is instead a dummy for being born in the birth cohort 1971-73. The probability of woman $i$ in cohort $c$ of being childless depends on her age and her birth cohort, which together determine whether this woman spent her late thirties during the Great Recession or before. The interaction coefficient $\delta_{D D}$ tells us the causal effect of being 34-39 during the crisis on the probability of still being childless at 37-39 year old. $X$ is a vector of additional observable determinants of childlessness added both to check the robustness of the results and to test the possible mechanisms through which the recession might affect childlessness. ${ }^{10}$

$$
\begin{aligned}
& \operatorname{Pr}(\text { Childless })_{i, c, t}=\alpha+\beta_{1} \text { Age37-39 } 9_{i, t}+\beta_{2} \text { Treat }_{c}+\delta_{D D}\left({\text { Age } \left.37-39_{i, t} * \text { Treat }_{c}\right)}+X_{i, t}+\varepsilon_{i, t}\right.
\end{aligned}
$$

To ensure the soundness of our DD design, first we test whether the parallel trend assumption is met. Second, we present descriptive statistics comparing the distribution of key variables across the treatment and control cohorts to show that they do not differ significantly in the main determinants of fertility. Finally, we introduce a random placebo treatment in 2004 in the following way: the group in the upper part of Fig. 1 is the placebo pseudo-cohort $(P)$ of women born in 1965-67 who, exactly like the control group, spend the time between 34 and 39 years old in a non-recession period. If the research design and the assumptions for the identification of the model are correct, replicating the DD analysis between the control and the placebo group should show no effect. 
Figure 2 illustrates graphically (fictitious data) the research design, which is slightly different from the typical DD analysis. As mentioned, our design could be defined as a 'treatment at a specific age with pseudo cohorts' since we compare women who enter their last years of reproductive life at the onset of the economic crisis with women who spend the same years just before the recession.

Each line in Fig. 2 represents one of the pseudo-cohorts selected: the black line is the treatment, the dark grey line with circles is the control and the light grey line represents the placebo, while the Y-axis shows the percentage of women without children in each group. First, the lines are downward sloping because we expect the proportion of childless women in each cohort to decline over time, since some of those women, with time, would have had children. Second, if the assumption of parallel trends holds, we expect these negatively sloped lines to be parallel, separated because of the cohort effects, but parallel. Third, notice that younger cohorts have smaller incidence of childlessness at all ages (e.g., in Fig. 2 the proportion of childless women at 34-36 is 34\% in the $\mathrm{P}$ group, $30 \%$ in the $\mathrm{C}$ group and $27 \%$ in the $\mathrm{T}$ group). This is a pattern we find in our data and is confirmed by official statistics (CPS report), as illustrated in more details in the next section (Fig. 3). Briefly, this is due to the fact that during the first years of the 2000s childlessness was slightly declining in every age group, except for women in their forties.

Finally, the straight black line after 2007 represents how actual data should look if the crisis had a negative effect on fertility (positive on childlessness), while the dotted black line represents the counterfactual. The latter is the trend childlessness would have had in the treatment group had the recession not happened, extrapolated from the control group.

We expect the model identification assumption to hold, namely we expect no systematic difference between treatment and control, because belonging to a certain birth cohort is randomly assigned and, therefore, the selection into treatment is also random. In other words, we assume that no unobserved shock, other than the treatment, happened between 2001 and 2010 that could have affected the outcome idiosyncratically in only one group and not in the other. ${ }^{11}$

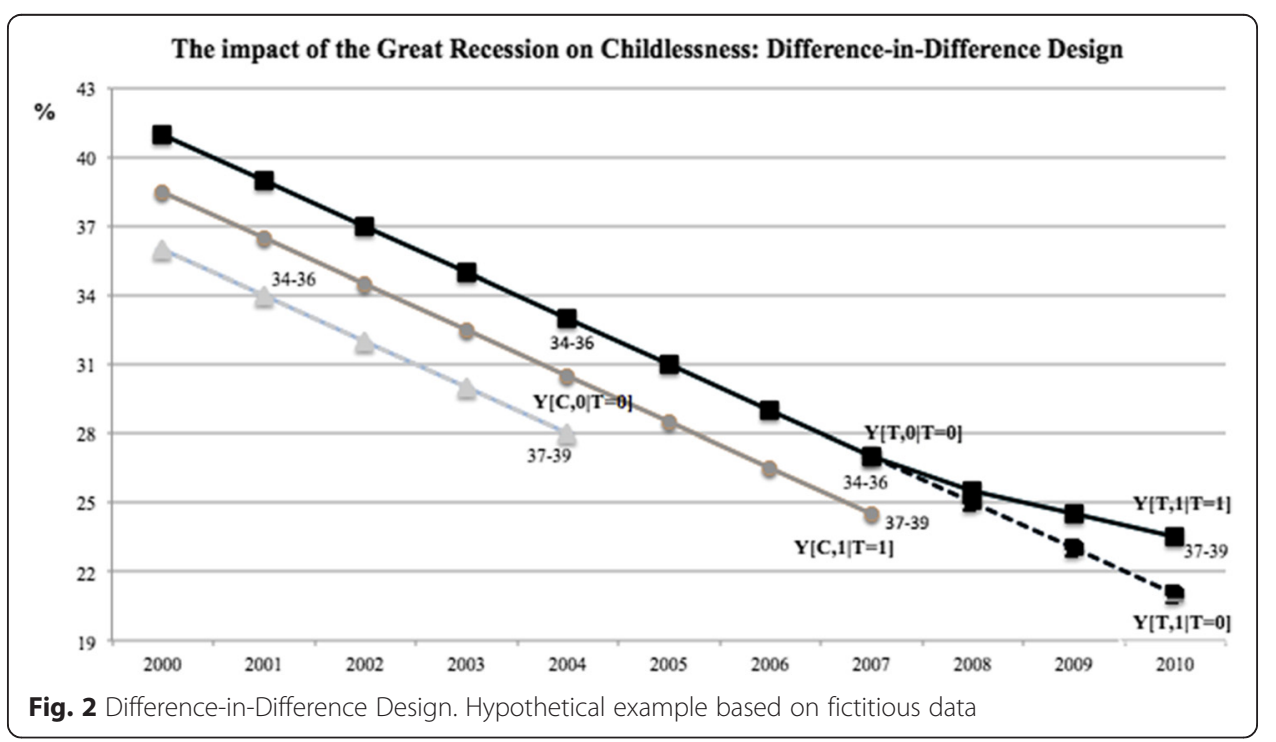




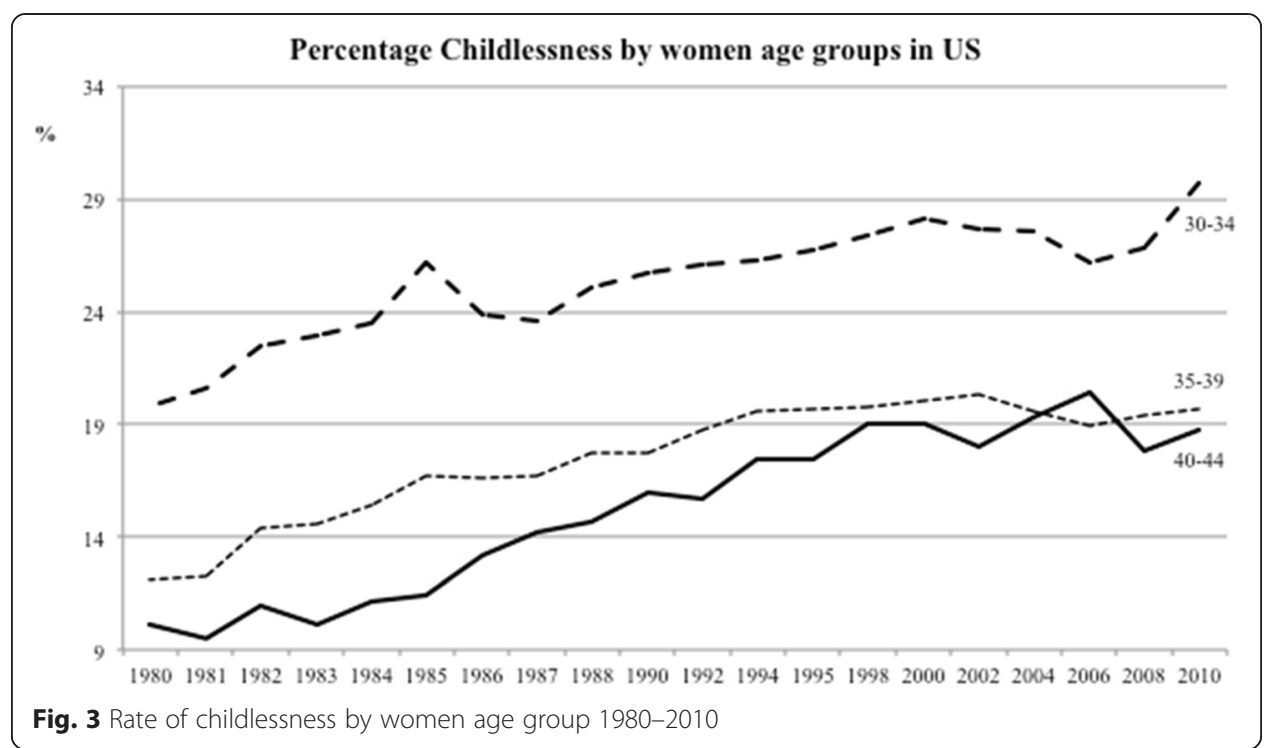

To the best of our knowledge, there are very few published papers combining, as done in the present study, the two approaches of DD and pseudo panels in population studies. Gahzal Naz (2004) investigates the impact of the cash benefit reforms in Norway on parents' labor force participation and couple specialization, and in a subsequent paper (Naz 2010) the same author compares the effect of the same Norwegian reform on the labor supply and earnings of native and immigrant women. In a very interesting paper, McKenzie (2003) analyzes family strategies, among which fertility choices, to cope with the Mexican peso crisis of the mid-nineties. The author compares the average number of children under the age of two, in different pseudo-cohorts, in the period 1994/1996 (births conceived before the onset of the crisis) versus 1996/1998 (births conceived after the onset of the recession). His DD analysis reveals that $5 \%$ of the households with a head aged 20-34 decided to postpone or renounce childbearing during the period of the crisis compared to the pre-crisis period.

\section{Childlessness in US census data}

As delayed childbearing has become more and more a typical phenomenon in the US like in other developed countries, births to older women are becoming a key point of interest to understand the dynamics of fertility and the changing population structure. According to the US National vital statistics (CDC/NCHS), first birth rates for women aged 35-39 started to increase in the mid-1970s and rose six-fold from 1973 to 2006, then slightly declined from 2006 to 2010 (from 10.9 to 10.4 per 1000 women), and increased again to 11.2 per 1000 women in $2013 .{ }^{12}$

As women postpone births, also the proportion of them remaining childless increases (Baudin et al 2015). As shown in Fig. 3, in 1980, only 10\% of women did not have children by the age of 40-44, while this percentage has grown to $19 \%$ in 2000 (CPS). For women in the age range of 35-39, in the same period 1980-2000, childlessness has similarly increased from $12 \%$ to around $20 \%$.

During the first years of the 2000s, the births postponed during the nineties started to be recuperated, and both rising fertility rates and declining childlessness rates were registered among all women in their thirties. However, after 2008 this decline halted 
and childlessness increased in all age groups, though more substantially for the younger group of women, 30-34 years old, and only mildly for the age group of our interest, the women aged 35-39. We thus expect to identify this postponement as translating into a positive effect of the crisis on childlessness rates of women in their late thirties.

Our DD and pseudo-panels design requires large $\mathrm{N}$ samples to avoid random fluctuations in the variable of interest from one year to the next. The American Community Survey (ACS) data is a component of the reengineered US Census, for which every year (since 2000) a sample of 3 million addresses is drawn from the Census Bureau's Master Address File (MAF), producing a sample of about $2.5 \%$ of the US population. ${ }^{13}$ The average number of family units actually interviewed each year is 2 million. Sample sizes of our three pseudo-panels of white American women in the ACS sample are illustrated in Table 1 (Panel A). ${ }^{14}$

Unfortunately, if on the one hand the ACS survey is very good in terms of sample size and geographic and year-to-year coverage, on the other hand, the main question of interest is posed in a less-than-optimal way. Namely, the questionnaire asks women about the number of own children residing in the household instead of the number of children ever had. The variable thus excludes children who moved out (most likely to college) and those children of divorced or separated mothers who live with the custodial father. ${ }^{15}$ Since we are working with differences, the exclusion of these two groups might invalidate the analysis only if the proportion of children not residing with the mother had changed during the recession period between 2007-2010, thus making the dependent variable in the treatment group differ in some way from the control group. If, for instance, college participation increased due to the crisis after 2007 and, also, these students were more likely to live on campus, then among the women declaring to be childless the proportion of those who actually have a child but he/she lives on campus would be higher in the treatment group. In this case we would be overestimating the positive effect of the recession on childlessness. The same is true if the crisis led to an increase in the proportion of children living with custodial fathers.

Therefore, to exclude any possible bias in the estimates, we checked the trends in the proportion of students leaving home for college and those of children residing with the custodial father. Data on American families' living arrangements, college enrollment and mobility ${ }^{16}$ suggest that, if something, the crisis had the effect of keeping children longer at their parents' house: the percentage of young adults living with their parents was $32 \%$ in 2007 and 36\% in 2012 (CPS), and choosing a college close to the parental house to keep living at home is one of the saving strategies more and more families adopt to afford children's college enrollment. As far as children in custody are

Table 1 Pseudo-panels size in the ACS (A) and CPS June fertility supplement (B)

\begin{tabular}{|c|c|c|c|c|c|c|c|c|c|c|c|c|c|c|}
\hline \multicolumn{7}{|l|}{ (A) } & \multicolumn{8}{|l|}{ (B) } \\
\hline Cohort & & 2001 & 2004 & 2007 & 2010 & Tot. & Cohort & & 1994 & 1998 & 2002 & 2006 & 2010 & Tot. \\
\hline & & & & & & & 1959-62 & $P_{2}$ & 4014 & 4025 & & & & 8039 \\
\hline $1965-67$ & P & 20283 & 19976 & & & 40259 & $1963-66$ & $P_{1}$ & & 3175 & 3789 & & & 6964 \\
\hline 1968-70 & C & & 19141 & 44764 & & 63905 & 1967-70 & C & & & 3334 & 3195 & & 6529 \\
\hline 1971-73 & $\mathrm{T}$ & & & 43006 & 43385 & 86391 & 1971-74 & $\mathrm{T}$ & & & & 2856 & 2851 & 5707 \\
\hline Tot. & & 20283 & 39117 & 87770 & 43385 & 190555 & Tot. & & 4014 & 7200 & 7123 & 6051 & 2851 & 27239 \\
\hline
\end{tabular}

Source: Elaboration of the author based on ACS and CPS June Fertility Supplement data 
concerned, the proportion of them that reside with the father has been quite stable in the last 10 years, around one out of six (CPS). In conclusion we do not expect the issues of college attendance and of fathers' custody to bias our estimates.

As a further check that our findings are not biased by measurement errors in the ACS questionnaire, we repeat the analysis on another US Census dataset: the June Fertility Supplement of the Current Population Survey (CPS), in which the question asked is whether women have ever had children. We did not prefer the CPS to the ACS in the first place because in the former the sample size is much smaller (around 55,000 households per year) and the fertility supplement is carried on only biennially (June CPS sample sizes reported in Panel B in Table 1). ${ }^{17}$

\section{Results}

We start from the ACS sample and then show that the results are very similar in the June CPS.

Figure 4 illustrates the trends in proportion of childless white women in the three pseudo-cohorts by age to graphically test the parallel trend assumption. The shortest line is the placebo cohort $(P) .{ }^{18}$ The dotted line is the control $(C)$, and the black line at the bottom is the treatment cohort $(T)$. Childlessness at $37-39$ is around $23-24 \%$ in all cohorts and, as expected, the proportion is declining within cohort, while increasing slightly only in the treatment cohort at the age of 37-39. The trends seem reasonably parallel between the control and placebo groups, and also for the treatment group until 2007, the year in which the cohort 1971-73 (T) turned 34-36. From that age onward the childlessness paths of the control and placebo groups remain parallel, while that of the treatment group deviates. Childless women are, more than would be expected, looking at previous cohorts in 2008, and the proportion keeps being higher also in 2010 and 2011.

When comparing the treatment and control groups at the age of 34-36 (when women enter in our study) on key determinants of fertility behavior, we find that the

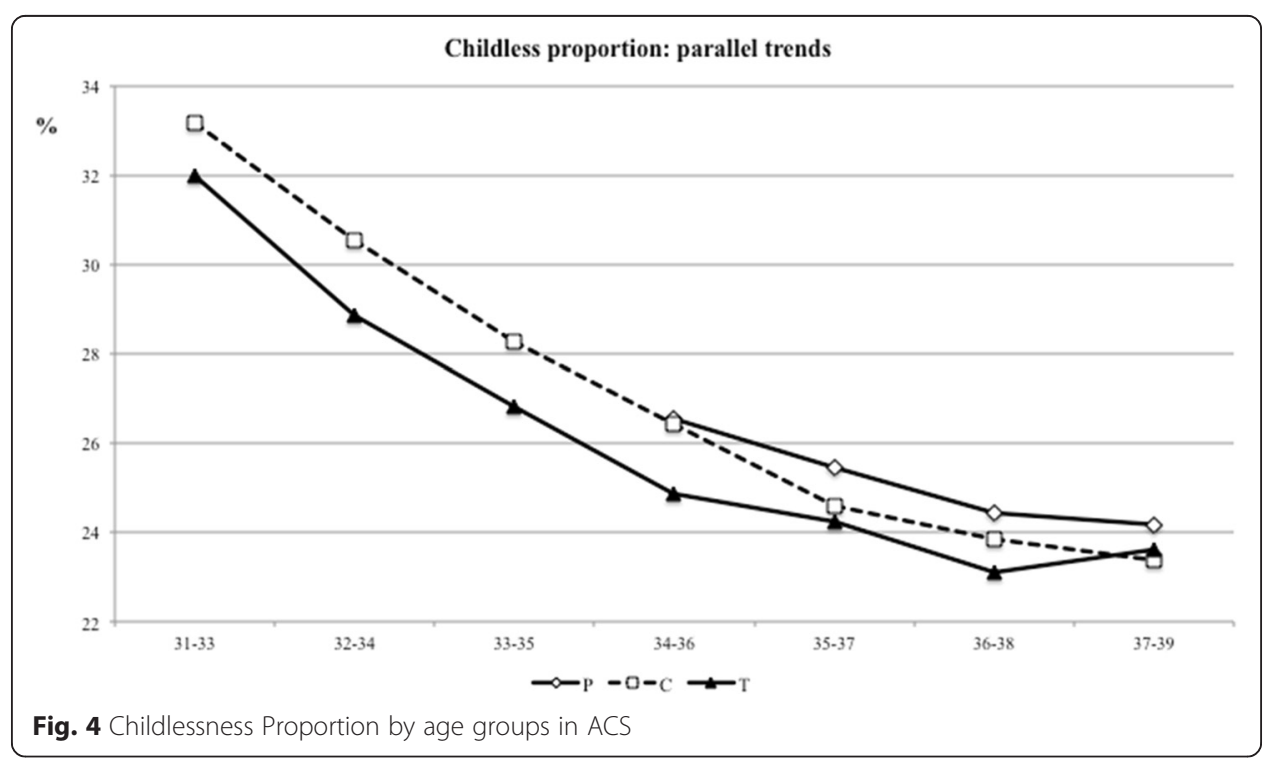


distribution across categories of marital status, educational attainment and employment status are almost identical across groups. ${ }^{19}$

Besides these descriptive speculations, Table 2 reports the DD causal estimate of a Linear Probability Model (LPM) of the treatment on women's probability of being childless in the ACS dataset (Treatment versus Control). Models (1) and (2) report the results of the main period effect, while models (3) to (5) show the effect of the recession mediated by controlling for education, marital status and employment status. The control variables are categorical and the reference categories are being married with the spouse present, being very low educated (less than high-school) and working.

The effect of the Great Recession on the probability of being childless for women aged $37-39$ is positive, though moderate, with a point estimate of $+1.8 / 1.9 \%$ depending on whether we control for state fixed effects or not. This effect is estimated quite accurately, with a confidence interval that ranges from $1 \%$ to $3 \%$.

The estimate is robust across models, also when controlling for state fixed effect, education, and marital and employment status. Marital status seems to be the stronger mediator of the effect of the recession on childlessness, reducing the effect to $+0.9 \%$ for married (spouse present) women. Any marital condition different from being married with a (present) spouse strongly increases the probability of being childless, with the singleton condition being the worst. Higher levels of education are also correlated with a larger probability of not having children, controlling for marital status (Model (4)). Compared to the working condition, having a job but not working and being out of the labor force are associated to lower rates of childlessness (Model (5)). Results regarding control variables are extremely robust across models.

Table 3 illustrates the results for the comparison between the Control and Placebo cohorts. As predicted by the assumptions of the model, the placebo treatment has no significant effect on the difference in childlessness between the control and placebo cohorts, statistically and substantially. Results do not change when adding controls in the placebo treatment, where the magnitude of the effect is still around zero and statistically insignificant.

To verify the robustness of our findings, we repeat the analysis on the CPS June Fertility Supplement, where the question asked to women is the number of children they ever had. Unfortunately, as mentioned, the CPS is conducted only biennially (even years), thus it is not possible to replicate the analysis in the exact same way in the two surveys. We can use 2010 as the post-treatment year as before, but we have to use 2006 as last pre-treatment year. This implies that we now need to form pseudo-panels of 4 birth-year cohorts. The treatment group is that of women born between 1971 and 1974 and the control group is that of women born in 1967-70: in the former group, women turn 36-39 in 2010, and in the latter they turn 36-39 in 2006.

With the CPS supplement we can go further back in time since the same survey was conducted also during the nineties. We thus can now have two placebo treatments and more points in time: the first placebo is the group of women born in 1963-66 and the second in 1959-62.

Except for these slight variations in the pseudo-cohorts though, the DD design is exactly the same as before. Therefore, we can compare the results in the two surveys with the different question on the dependent variable and check if the effect of the Great Recession on childlessness identified in the ACS is robust. 
Table 2 Difference-in-difference estimates of the effect of the great recession on women's probability of being childless at 34-39. Linear probability models (ACS data)

\begin{tabular}{|c|c|c|c|c|c|}
\hline & \multicolumn{5}{|c|}{ Treatment versus Control $^{a}$} \\
\hline & Model & Model & Model & Model & Model \\
\hline & $(1)$ & $(2)$ & (3) & (4) & $(5)$ \\
\hline \multirow[t]{2}{*}{ Age $37-39^{b}$} & $-0.031^{* * *}$ & $-0.032^{* * *}$ & $-0.031^{* * *}$ & $-0.021^{* * *}$ & $-0.022^{* * *}$ \\
\hline & $(-0.038--0.023)$ & $(-0.040--0.025)$ & $(-0.039--0.024)$ & $(-0.027--0.015)$ & $(-0.029--0.016)$ \\
\hline \multirow[t]{2}{*}{ Treatment cohort } & $-0.016^{* * *}$ & $-0.017^{* * *}$ & $-0.017^{* * *}$ & $-0.019^{* * *}$ & $-0.019^{* * *}$ \\
\hline & $(-0.023--0.008)$ & $(-0.024--0.009)$ & $(-0.024--0.010)$ & $(-0.025--0.012)$ & $(-0.026--0.013)$ \\
\hline DD (Age 37-39* & $0.018^{* * *}$ & $0.019^{* * *}$ & $0.019^{* * *}$ & $0.009^{* *}$ & $0.008^{* *}$ \\
\hline Treatment cohort) & $(0.009-0.028)$ & $(0.010-0.028)$ & $(0.010-0.028)$ & $(0.001-0.017)$ & $(0.000-0.016)$ \\
\hline \multicolumn{6}{|l|}{ Education $^{c}$} \\
\hline \multirow[t]{2}{*}{ Completed Highschool } & & & $-0.010^{* *}$ & $0.020^{* * *}$ & $0.008^{*}$ \\
\hline & & & $(-0.019--0.001)$ & $(0.012-0.028)$ & $(-0.000-0.016)$ \\
\hline \multirow[t]{2}{*}{ Some college but no degree } & & & $-0.022^{* * *}$ & $0.018^{* * *}$ & 0.004 \\
\hline & & & $(-0.031--0.013)$ & $(0.010-0.026)$ & $(-0.005-0.012)$ \\
\hline \multirow[t]{2}{*}{ Associate's degree } & & & $-0.031^{* * *}$ & $0.020^{* * *}$ & 0.002 \\
\hline & & & $(-0.041--0.021)$ & $(0.011-0.029)$ & $(-0.007-0.012)$ \\
\hline \multirow[t]{2}{*}{ Bachelor's degree } & & & $0.023^{* * *}$ & $0.078^{* * *}$ & $0.063^{* * *}$ \\
\hline & & & $(0.014-0.032)$ & $(0.070-0.086)$ & $(0.054-0.071)$ \\
\hline \multirow[t]{2}{*}{ Master's degree or higher } & & & $0.063^{* * *}$ & $0.110^{* * *}$ & $0.090^{* * *}$ \\
\hline & & & $(0.053-0.073)$ & $(0.102-0.119)$ & $(0.082-0.099)$ \\
\hline \multicolumn{6}{|l|}{ Marital Status $^{d}$} \\
\hline \multirow[t]{2}{*}{ Married, spouse absent } & & & & $0.336^{* * *}$ & $0.335^{* * *}$ \\
\hline & & & & $(0.315-0.357)$ & $(0.314-0.356)$ \\
\hline \multirow[t]{2}{*}{ Separated } & & & & $0.128^{* * *}$ & $0.122^{* * *}$ \\
\hline & & & & $(0.116-0.141)$ & $(0.109-0.135)$ \\
\hline Divorced & & & & $0.237^{* * *}$ & $0.228^{* * *}$ \\
\hline
\end{tabular}


Table 2 Difference-in-difference estimates of the effect of the great recession on women's probability of being childless at 34-39. Linear probability models (ACS data) (Continued)

\begin{tabular}{|c|c|c|c|c|c|}
\hline & & & & $(0.230-0.245)$ & $(0.221-0.235)$ \\
\hline \multirow[t]{2}{*}{ Widowed } & & & & $0.133^{* * *}$ & $0.134^{* * *}$ \\
\hline & & & & $(0.106-0.160)$ & $(0.107-0.161)$ \\
\hline \multirow[t]{2}{*}{ Never married/single } & & & & $0.622^{* * *}$ & $0.614^{* * *}$ \\
\hline & & & & $(0.616-0.628)$ & $(0.607-0.620)$ \\
\hline \multicolumn{6}{|l|}{ Employment Status $^{\mathrm{e}}$} \\
\hline \multirow[t]{2}{*}{ Has a job, not working } & & & & & $-0.047^{* * *}$ \\
\hline & & & & & $(-0.059--0.035)$ \\
\hline \multirow[t]{2}{*}{ Armed forces, at work } & & & & & 0.028 \\
\hline & & & & & $(-0.033-0.090)$ \\
\hline \multirow[t]{2}{*}{ Armed forces, not at work but with job } & & & & & $-0.202^{* * *}$ \\
\hline & & & & & $(-0.235--0.169)$ \\
\hline \multirow[t]{2}{*}{ Unemployed } & & & & & $-0.010^{*}$ \\
\hline & & & & & $(-0.021-0.000)$ \\
\hline \multirow[t]{2}{*}{ Not in the labor force } & & & & & $-0.064^{* * *}$ \\
\hline & & & & & $(-0.068--0.060)$ \\
\hline State fixed effects & No & Yes & No & No & No \\
\hline \multirow[t]{2}{*}{ Constant } & $0.264^{* * *}$ & $0.230^{* * *}$ & $0.261^{* * *}$ & $0.100^{* * *}$ & $0.135^{* * *}$ \\
\hline & $(0.258-0.271)$ & $(0.212-0.248)$ & $(0.251-0.271)$ & $(0.091-0.108)$ & $(0.126-0.144)$ \\
\hline N & 150296 & 150296 & 150296 & 150296 & 150296 \\
\hline
\end{tabular}

Source: Elaboration of the author based on ACS data

In the Treatment group women turn 37-39 in 2010 while in the Control group women turn 37-39 in 2007

${ }^{b}$ Reference category is Age group 34-36

'Reference category is Less than High school

${ }^{\mathrm{d}}$ Reference category is Married with spouse present

${ }^{\mathrm{e}}$ Reference category is working

${ }^{*} p \leq 0.05,{ }^{* *} p \leq 0.01,{ }^{* * *} p \leq 0.001$. Robust Confidence Intervals in parenthesis 
Table 3 Difference-in-Difference estimates of the effect of the Great Recession on women's probability of being childless at 34-39. Linear Probability Models (ACS data)

\begin{tabular}{|c|c|c|c|c|c|}
\hline & \multicolumn{5}{|c|}{ Placebo versus Control $^{a}$} \\
\hline & Model & Model & Model & Model & Model \\
\hline & (1) & (2) & (3) & (4) & (5) \\
\hline \multirow[t]{2}{*}{ Age $37-39^{b}$} & $-0.024^{* * *}$ & $-0.023^{* * *}$ & $-0.025^{* * *}$ & $-0.015^{* * *}$ & $-0.015^{* * *}$ \\
\hline & $(-0.032--0.015)$ & $(-0.032--0.015)$ & $(-0.033--0.017)$ & $(-0.022--0.008)$ & $(-0.022--0.008)$ \\
\hline \multirow[t]{2}{*}{ Placebo Cohort } & -0.001 & -0.001 & -0.004 & -0.006 & -0.005 \\
\hline & $(-0.010-0.007)$ & $(-0.010-0.007)$ & $(-0.013-0.004)$ & $(-0.013-0.002)$ & $(-0.013-0.002)$ \\
\hline \multirow[t]{2}{*}{ DD (age 37-39* Placebo Cohort) } & -0.007 & -0.009 & -0.006 & -0.005 & -0.007 \\
\hline & $(-0.018-0.004)$ & $(-0.020-0.002)$ & $(-0.018-0.005)$ & $(-0.015-0.004)$ & $(-0.017-0.003)$ \\
\hline \multicolumn{6}{|l|}{ Education $^{c}$} \\
\hline \multirow[t]{2}{*}{ Completed Highschool } & & & $-0.020^{* * *}$ & $0.015^{* * *}$ & 0.002 \\
\hline & & & $(-0.031--0.009)$ & $(0.005-0.024)$ & $(-0.008-0.012)$ \\
\hline \multirow[t]{2}{*}{ Some college but no degree } & & & $-0.024^{* * *}$ & $0.014^{* * *}$ & -0.001 \\
\hline & & & $(-0.035--0.013)$ & $(0.004-0.024)$ & $(-0.011-0.009)$ \\
\hline \multirow[t]{2}{*}{ Associate's degree } & & & $-0.027^{* * *}$ & $0.021^{* * *}$ & 0.002 \\
\hline & & & $(-0.039--0.014)$ & $(0.010-0.032)$ & $(-0.009-0.014)$ \\
\hline \multirow[t]{2}{*}{ Bachelor's degree } & & & $0.025^{* * *}$ & $0.070^{* * *}$ & $0.055^{* * *}$ \\
\hline & & & $(0.014-0.036)$ & $(0.060-0.080)$ & $(0.045-0.065)$ \\
\hline \multirow[t]{2}{*}{ Master's degree or higher } & & & $0.070^{* * *}$ & $0.101^{* * *}$ & $0.082^{* * *}$ \\
\hline & & & $(0.058-0.083)$ & $(0.090-0.112)$ & $(0.071-0.093)$ \\
\hline \multicolumn{6}{|l|}{ Marital Status $^{d}$} \\
\hline \multirow[t]{2}{*}{ Married, spouse absent } & & & & $0.351^{* * *}$ & $0.350^{* * *}$ \\
\hline & & & & $(0.325-0.378)$ & $(0.324-0.377)$ \\
\hline \multirow[t]{2}{*}{ Separated } & & & & $0.124^{* * *}$ & $0.117^{* * *}$ \\
\hline & & & & $(0.108-0.140)$ & $(0.101-0.133)$ \\
\hline Divorced & & & & $0.234^{* * *}$ & $0.224^{* * *}$ \\
\hline
\end{tabular}


Table 3 Difference-in-Difference estimates of the effect of the Great Recession on women's probability of being childless at 34-39. Linear Probability Models (ACS data) (Continued)

\begin{tabular}{|c|c|c|c|c|c|}
\hline & & & & $(0.225-0.242)$ & $(0.215-0.232)$ \\
\hline \multirow[t]{2}{*}{ Widowed } & & & & $0.136^{* * *}$ & $0.136^{* * *}$ \\
\hline & & & & $(0.103-0.169)$ & $(0.103-0.169)$ \\
\hline \multirow[t]{2}{*}{ Never married/single } & & & & $0.640^{* * *}$ & $0.631^{* * *}$ \\
\hline & & & & $(0.633-0.648)$ & $(0.624-0.639)$ \\
\hline \multicolumn{6}{|l|}{ Employment Status ${ }^{\mathrm{e}}$} \\
\hline \multirow[t]{2}{*}{ Has a job, not working } & & & & & $-0.047^{* * *}$ \\
\hline & & & & & $(-0.060--0.033)$ \\
\hline \multirow[t]{2}{*}{ Armed forces, at work } & & & & & 0.025 \\
\hline & & & & & $(-0.048-0.097)$ \\
\hline \multirow{2}{*}{$\begin{array}{l}\text { Armed forces, not at } \\
\text { work but with job }\end{array}$} & & & & & $-0.221^{* * *}$ \\
\hline & & & & & $(-0.230--0.213)$ \\
\hline \multirow[t]{2}{*}{ Unemployed } & & & & & -0.009 \\
\hline & & & & & $(-0.023-0.005)$ \\
\hline \multirow[t]{2}{*}{ Not in the labor force } & & & & & $-0.068^{* * *}$ \\
\hline & & & & & $(-0.073--0.063)$ \\
\hline State Fixed Effects & No & Yes & No & No & No \\
\hline \multirow[t]{2}{*}{ Constant } & $0.266^{* * *}$ & $0.234^{* * *}$ & $0.267^{* * *}$ & $0.109^{* * *}$ & $0.144^{* * *}$ \\
\hline & $(0.260-0.272)$ & $(0.211-0.257)$ & $(0.256-0.278)$ & $(0.099-0.118)$ & $(0.134-0.155)$ \\
\hline N & 104164 & 104164 & 104164 & 104164 & 104164 \\
\hline
\end{tabular}

Source: Elaboration of the author based on ACS data

aln the Control group women turn 37-39 in 2007 while in the Placebo group women turn 37-39 in 2004

${ }^{b}$ Reference category is Age group 34-36

'Reference category is Less than High school

${ }^{\mathrm{d}}$ Reference category is Married with spouse present

${ }^{e}$ Reference category is working

${ }^{*} p \leq 0.05,{ }^{* *} p \leq 0.01,{ }^{* *} p \leq 0.001$. Robust Confidence intervals in parenthesis 
Figure 5 is the analogous of Fig. 4 for the June CPS supplement dataset with the proportion of childless women in each cohort and age group. We now have two placebos (the two dotted lines in Fig. 5) and the cohort trends seem reasonably parallel but more overlapping here in the CPS datasets compared to the ACS survey. The proportion of childless women by age groups is smaller in the CPS sample, compared to the ACS, because of the different way the fertility question is posed in the two surveys. Nonetheless, the cohort trends are pretty similar: in all cohorts but the treatment, the proportion of childless women between the early and the late thirties declines by about a $5 \%$, with only the younger cohort making the transition during the recession registering a difference of less than $2 \%$.

The DD estimates reported in Table 4 confirm this fact. The point estimate of the effect on the treatment here is slightly larger than before even though less precisely estimated: childlessness is $3.2 \%$ higher than what it would have likely been in the absence of the Great Recession, controlling or not for state fixed effect (Models (1)-(2)). However, adding the mediating variable-marital status-the effect becomes statistically insignificant (but still positive at two percent). ${ }^{20}$ Confidence intervals are larger compared to the ACS sample where the sample size was much bigger: the lower bound estimate is slightly above zero, while the upper bound gets to five or six percent depending on the model. Importantly, as shown in Table 5, the placebo treatment DD estimates are again substantially close to zero, and the point estimates are statistically nonsignificant. ${ }^{21}$

The larger size of the effect in the CPS compared to the ACS might be due to the different way the question is posed in the surveys. As argued before, the recession-if anything-had the effect of keeping children at home longer than before. This means that the estimates of childlessness in the ACS sample are a lower bound of the effect since more women might be classified as childless when they are not in the waves preceding the recession compared to waves after 2008. However, probably due to the smaller sample size, the CPS dataset yields imprecise point estimates of the effect.

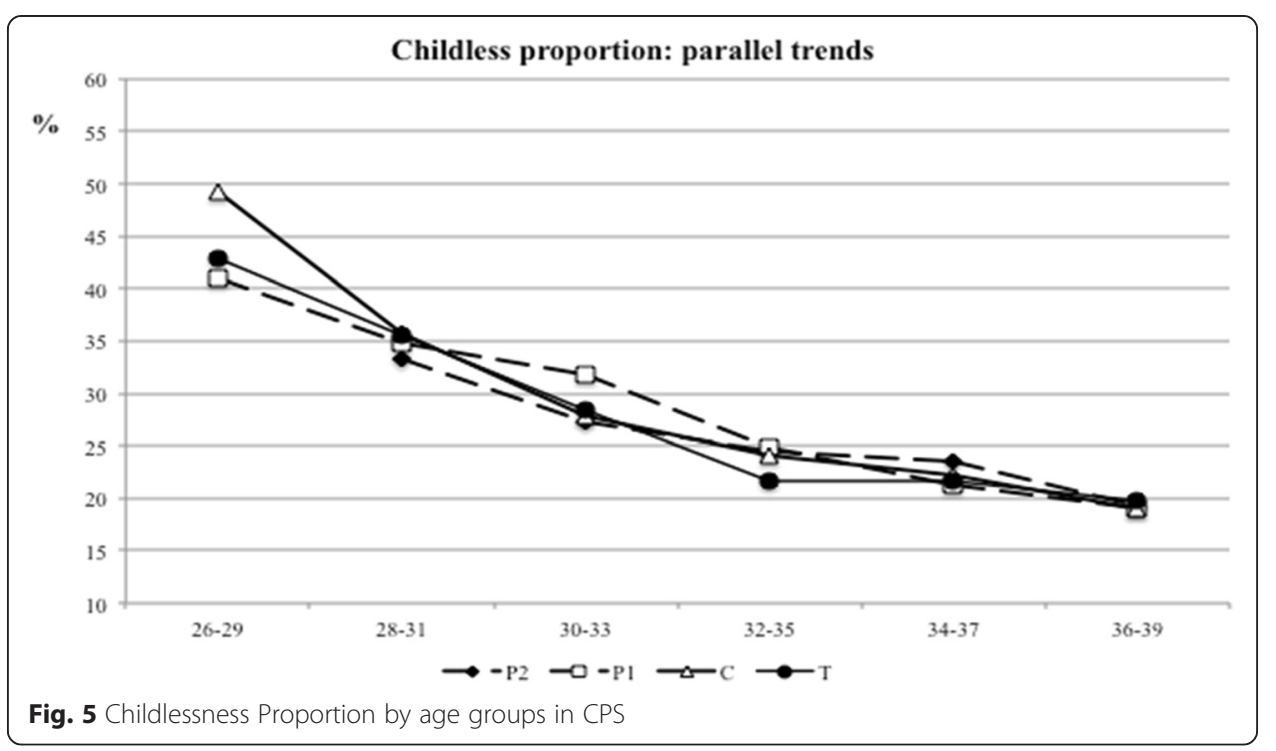


Table 4 Difference-in-difference estimates of the effect of the great recession on women's probability of being childless at 32-39. Linear probability models (CPS Fertility Supplement data)

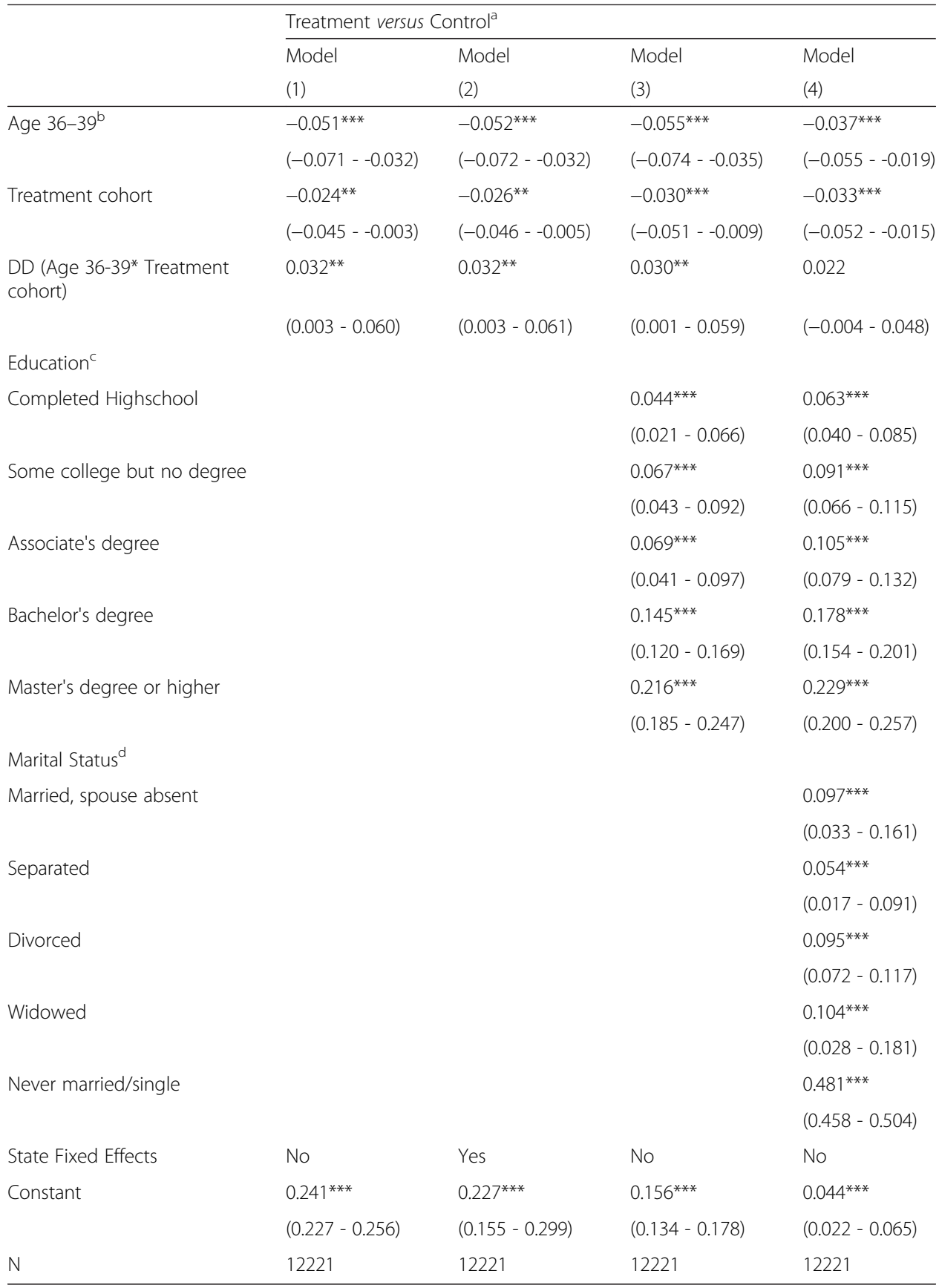

Source: Elaboration of the author based on CPS June Fertility Supplement data

${ }^{*} p \leq 0.05,{ }^{* *} p \leq 0.01,{ }^{* * *} p \leq 0.001$. Robust Confidence intervals in parenthesis

${ }^{a}$ In the Treatment group women turn 36-39 in 2010 while in the Control group women turn 36-39 in 2006

${ }^{\mathrm{b}}$ Reference category is Age group 32-35

'Reference category is Less than High school

${ }^{\mathrm{d}}$ Reference category is Married with spouse present

\section{Complementary analyses}

We have replicated the DD analysis on different age groups of white American women, both younger and older than the 37-39 group considered in the previous section. Table 6 illustrates the magnitude of the causal effect estimated exactly in the same way 
Table 5 Difference-in-difference estimates of the effect of the great recession on women's probability of being childless at 32-39. Linear probability models (CPS Fertility Supplement data)

\begin{tabular}{|c|c|c|c|c|}
\hline & \multicolumn{4}{|c|}{ Control versus Placebo $1^{a}$} \\
\hline & Model & Model & Model & Model \\
\hline & (1) & (2) & (3) & (4) \\
\hline \multirow[t]{2}{*}{ Age $36-39^{b}$} & $-0.057^{* * *}$ & $-0.060^{* * *}$ & $-0.061^{* * *}$ & $-0.038^{* * *}$ \\
\hline & $(-0.077--0.038)$ & $(-0.079--0.040)$ & $(-0.080--0.042)$ & $(-0.055--0.021)$ \\
\hline \multirow[t]{2}{*}{ Treatment cohort } & -0.007 & -0.010 & -0.011 & -0.008 \\
\hline & $(-0.028-0.014)$ & $(-0.031-0.011)$ & $(-0.032-0.009)$ & $(-0.026-0.010)$ \\
\hline \multirow[t]{2}{*}{ DD (Age 36-39* Treatment cohort) } & 0.006 & 0.008 & 0.006 & 0.003 \\
\hline & $(-0.022-0.034)$ & $(-0.020-0.036)$ & $(-0.021-0.034)$ & $(-0.022-0.027)$ \\
\hline \multicolumn{5}{|l|}{ Education $^{c}$} \\
\hline \multirow[t]{2}{*}{ Completed Highschool } & & & $0.035^{* * *}$ & $0.068^{* * *}$ \\
\hline & & & $(0.014-0.057)$ & $(0.047-0.088)$ \\
\hline \multirow[t]{2}{*}{ Some college but no degree } & & & $0.055^{* * *}$ & $0.090^{* * *}$ \\
\hline & & & $(0.031-0.079)$ & $(0.068-0.113)$ \\
\hline \multirow[t]{2}{*}{ Associate's degree } & & & $0.067^{* * *}$ & $0.102^{* * *}$ \\
\hline & & & $(0.040-0.095)$ & $(0.077-0.128)$ \\
\hline \multirow[t]{2}{*}{ Bachelor's degree } & & & $0.165^{* * *}$ & $0.188^{* * *}$ \\
\hline & & & $(0.140-0.189)$ & $(0.165-0.210)$ \\
\hline \multirow[t]{2}{*}{ Master's degree or higher } & & & $0.220^{* * *}$ & $0.231^{* * *}$ \\
\hline & & & $(0.188-0.253)$ & $(0.202-0.260)$ \\
\hline \multicolumn{5}{|l|}{ Marital Status ${ }^{d}$} \\
\hline \multirow[t]{2}{*}{ Married, spouse absent } & & & & $0.080^{* *}$ \\
\hline & & & & $(0.016-0.145)$ \\
\hline \multirow[t]{2}{*}{ Separated } & & & & 0.023 \\
\hline & & & & $(-0.008-0.055)$ \\
\hline \multirow[t]{2}{*}{ Divorced } & & & & $0.083^{* * *}$ \\
\hline & & & & $(0.063-0.104)$ \\
\hline \multirow[t]{2}{*}{ Widowed } & & & & $0.125^{* * *}$ \\
\hline & & & & $(0.049-0.200)$ \\
\hline \multirow[t]{2}{*}{ Never married/single } & & & & $0.540^{* * *}$ \\
\hline & & & & $(0.519-0.562)$ \\
\hline State Fixed Effects & No & Yes & No & No \\
\hline \multirow[t]{2}{*}{ Constant } & $0.248^{* * *}$ & $0.178^{* * *}$ & $0.167^{* * *}$ & $0.041^{* * *}$ \\
\hline & $(0.233-0.263)$ & $(0.121-0.236)$ & $(0.145-0.189)$ & $(0.020-0.062)$ \\
\hline N & 13476 & 13476 & 13476 & 13476 \\
\hline
\end{tabular}

Source: Elaboration of the author based on CPS June Fertility Supplement data

an the Control group women turn 36-39 in 2006 while in the Placebo group women turn 36-39 in 2002

${ }^{\mathrm{b}}$ Reference category is Age group 32-35

'Reference category is Less than High school

${ }^{d}$ Reference category is Married with spouse present

${ }^{*} p \leq 0.05,{ }^{* *} p \leq 0.01,{ }^{* * *} p \leq 0.001$. Robust Confidence intervals in parenthesis

as it was presented in Models (1)-(2) in Tables 2, 3, 4 and 5 but for different pseudocohorts of women (ACS in Panel (a) and CPS in Panel (b)). Placebo treatment estimates are also presented in the cases in which we find an effect on the treatment group.

In both samples we find an effect of the Great Recession on the probability of remaining childless for women in their thirties. The magnitude of the effect is also 
Table 6 Difference-in-difference estimates of the effect of the great recession on women's probability of being childless (LPM) varying the age range in ACS (a) and in CPS (b)

\begin{tabular}{|c|c|c|c|c|}
\hline \multicolumn{5}{|l|}{ (a) } \\
\hline Cohorts & Age at Treatment in 2007 & Age in 2010 & $\begin{array}{l}\text { Treatment Effect Probability } \\
\text { of Childlessness }\end{array}$ & Placebo Treatment Effect \\
\hline 1966-68 & $39-41$ & $42-44$ & -.004 & - \\
\hline 1967-69 & $38-40$ & $41-43$ & -.001 & - \\
\hline 1968-70 & $37-39$ & $40-42$ & -.003 & - \\
\hline 1969-71 & $36-38$ & $39-41$ & +.002 & - \\
\hline 1970-72 & $35-37$ & $38-40$ & +.003 & - \\
\hline $1971-73$ & $34-36$ & $37-39$ & $+.018^{* * *} /+.019^{* * *}$ & $-.009 /+.013$ \\
\hline $1972-74$ & $33-35$ & $36-38$ & $+.017^{* * *} /+.018^{* * *}$ & $-.005 /-.007$ \\
\hline 1973-75 & $32-34$ & $35-37$ & $+.014^{* * *} /+.015^{* * *}$ & $.004 / .001$ \\
\hline 1974-76 & $31-33$ & $34-36$ & $+.010^{*} /+.012^{* *}$ & $-.004 /-.007$ \\
\hline \multicolumn{5}{|l|}{ (b) } \\
\hline Cohorts & Age at Treatment in 2006 & Age in 2010 & $\begin{array}{l}\text { Treatment Effect Probability } \\
\text { of Childlessness }\end{array}$ & Placebo Treatment Effect \\
\hline 1966-69 & $37-40$ & $41-44$ & -.021 & - \\
\hline $1967-70$ & $36-39$ & $40-43$ & -.006 & - \\
\hline 1968-71 & $35-38$ & $39-42$ & -.005 & - \\
\hline 1969-72 & $34-37$ & $38-41$ & +.003 & - \\
\hline 1970-73 & $33-36$ & $37-40$ & +.013 & - \\
\hline 1971-74 & $32-35$ & $36-39$ & $+.030^{* *} /+.032^{* *}$ & $-.001 /+.006$ \\
\hline $1972-75$ & $31-34$ & $35-38$ & $+.034^{* *} /+.036^{* *}$ & $-.007 /-.006$ \\
\hline $1973-76$ & $30-33$ & $34-37$ & $+.040^{* * *}$ & $-.015 /-.016$ \\
\hline
\end{tabular}

Source: Elaboration of the author based on ACS and CPS June Fertility Supplement data ${ }^{*} p \leq 0.05,{ }^{* *} p \leq 0.01,{ }^{* * *} p \leq 0.001$

quite robust, ranging from $1-2 \%$ in the ACS sample, depending on the age of women and the model specification, to $3-4 \%$ in the CPS June Fertility Supplement. On the other hand, no effect is found when we consider age groups older than 40. This result is in line with previous findings that suggest that economic downturns mainly have an effect on fertility postponement at younger ages (Currie and Schwandt 2014).

Finally, we have complemented our DD analysis with a study of the effect of unemployment rates on childlessness, controlling for other unobservable traits common to the year and state of residence. Table 7 presents the estimates of a Linear Probability Model on the probability of being childless at age 37-39 with year and state fixed effects. Model (1) shows the effect of the state unemployment rate in the year $t$ on the probability of being childless in the year $t+1$. In the next models, (2) to (4), we add controls at the individual level. In none of these specifications do we find any effect of the state unemployment rate. We do find that being unemployed is associated to about a 3 percentage points higher probability of being childless, although this association vanishes once marital status is included in the model. We have changed the bandwidth of the age group $(37-40,36-40,36-41)$ and the results do not change. ${ }^{22}$ We have also replicated the analyses for different age groups (20-24, 25-29 and 30-34). ${ }^{23}$ In line with previous studies (Currie and Schwandt 2014) we do, however, find a positive association between the state level of unemployment and childlessness among younger women aged 20 to 24 . All in all, still, these results suggest that the effect of the Great 
Table 7 Complementary analysis on the effect of state unemployment rate on childlessness. Linear probability models (ACS)

\begin{tabular}{|c|c|c|c|c|}
\hline & \multicolumn{4}{|c|}{ 37-39 year old women } \\
\hline & \multirow{2}{*}{$\begin{array}{l}\text { Model } \\
\text { (1) }\end{array}$} & \multirow{2}{*}{$\begin{array}{l}\text { Model } \\
\text { (2) }\end{array}$} & \multirow{2}{*}{$\begin{array}{l}\text { Model } \\
\text { (3) }\end{array}$} & \multirow{2}{*}{$\begin{array}{l}\text { Model } \\
\text { (4) }\end{array}$} \\
\hline & & & & \\
\hline Mean-cent. State Unemployment & -0.001 & -0.001 & $-0.002^{*}$ & $-0.002^{* * *}$ \\
\hline rate (lagged) & $(-0.003-0.000)$ & $(-0.003-0.000)$ & $(-0.003-0.000)$ & $(-0.004--0.001)$ \\
\hline \multicolumn{5}{|l|}{ Education $^{\text {b }}$} \\
\hline \multirow[t]{2}{*}{ Completed Highschool } & & -0.004 & $-0.021^{* * *}$ & $0.016^{* * *}$ \\
\hline & & $(-0.010-0.001)$ & $(-0.026--0.015)$ & $(0.011-0.020)$ \\
\hline \multirow[t]{2}{*}{ Some college but no degree } & & $-0.024^{* * *}$ & $-0.043^{* * *}$ & 0.002 \\
\hline & & $(-0.029--0.018)$ & $(-0.049--0.038)$ & $(-0.003-0.007)$ \\
\hline \multirow[t]{2}{*}{ Associate's degree } & & $-0.029^{* * *}$ & $-0.053^{* * *}$ & $0.005^{*}$ \\
\hline & & $(-0.035--0.023)$ & $(-0.059--0.047)$ & $(-0.000-0.011)$ \\
\hline \multirow[t]{2}{*}{ Bachelor's degree } & & $0.006^{* *}$ & $-0.014^{* * *}$ & $0.046^{* * *}$ \\
\hline & & $(0.000-0.011)$ & $(-0.019--0.008)$ & $(0.041-0.051)$ \\
\hline \multirow[t]{2}{*}{ Master's degree or higher } & & $0.038^{* * *}$ & $0.011^{* * *}$ & $0.069^{* * *}$ \\
\hline & & $(0.032-0.044)$ & $(0.005-0.017)$ & $(0.064-0.075)$ \\
\hline \multicolumn{5}{|l|}{ Employment status $^{c}$} \\
\hline \multirow[t]{2}{*}{ Unemployed } & & & $0.030^{* * *}$ & -0.002 \\
\hline & & & $(0.024-0.037)$ & $(-0.009-0.004)$ \\
\hline \multirow[t]{2}{*}{ Not in labor force } & & & $-0.101^{* * *}$ & $-0.052^{* * *}$ \\
\hline & & & $(-0.104--0.098)$ & $(-0.055--0.050)$ \\
\hline \multicolumn{5}{|l|}{ Marital status ${ }^{d}$} \\
\hline \multirow[t]{2}{*}{ Married, spouse absent } & & & & $0.334^{* * *}$ \\
\hline & & & & $(0.321-0.346)$ \\
\hline \multirow[t]{2}{*}{ Separated } & & & & $0.126^{* * *}$ \\
\hline & & & & $(0.118-0.133)$ \\
\hline \multirow[t]{2}{*}{ Divorced } & & & & $0.228^{* * *}$ \\
\hline & & & & $(0.224-0.232)$ \\
\hline \multirow[t]{2}{*}{ Widowed } & & & & $0.167^{* * *}$ \\
\hline & & & & $(0.151-0.182)$ \\
\hline \multirow[t]{2}{*}{ Never married/single } & & & & $0.620^{* * *}$ \\
\hline & & & & $(0.616-0.624)$ \\
\hline Year Fixed Effect ${ }^{e}$ & Yes & Yes & Yes & Yes \\
\hline State Fixed Effect ${ }^{f}$ & Yes & Yes & Yes & Yes \\
\hline \multirow[t]{2}{*}{ Constant } & $0.212^{* * *}$ & $0.215^{* * *}$ & $0.258^{* * *}$ & $0.113^{* * *}$ \\
\hline & $(0.200-0.223)$ & $(0.203-0.227)$ & $(0.246-0.271)$ & $(0.102-0.125)$ \\
\hline N & 437637 & 435697 & 435697 & 435697 \\
\hline
\end{tabular}

Source: Elaboration of the author based on ACS data

${ }^{a}$ Mean state unemployment rate in the period $2000-2012$ is $6.36 \%$

${ }^{\mathrm{b}}$ Reference category is Less than High school

${ }^{\mathrm{c}}$ Reference category is being employed

${ }^{\mathrm{d}}$ Reference category is Married with spouse present

' $Y$ ears available are 2000-2012, the reference year is 2010

Reference state is Alabama

${ }^{*} p \leq 0.05,{ }^{* *} p \leq 0.01,{ }^{* * *} p \leq 0.001$. Robust Confidence intervals in parenthesis. The analysis on different age groups and varying the bandwidth yield very similar results and are available in the Appendix 
Recession for the cohort of women born between 1971 and 1973 found in the DD analysis is not spurred by an increase in the unemployment level at the state level. Other mechanisms, such as a perceived sense of economic insecurity throughout the country, might account for the reduction in childbearing among women in their middle and late thirties.

\section{Discussion and conclusion}

This paper investigates the causal effect of the Great Recession on the postponement of first births by American white women in their thirties.

To estimate this outcome we present a novel design where the identification of the causal effect is conducted exploiting a 'treatment at a specific age with pseudo cohorts' and applying the difference-in-difference (DD) technique to pseudo-cohorts of white American women. Women are not compared across space, as in traditional DD models, but across age-periods: the treatment group is composed of white women 37-39 years old in 2010, while in the control group women turn the same age in 2007, before the onset of the crisis. We measure cohorts' childlessness rates for the treatment group between 2007 and 2010, whereas we look between 2004 and 2007 for the control group who have spent their late thirties not during the recession period but just before.

The DD analysis shows a positive, though mild, effect: depending on the sample, the main period effect of the crisis on the proportion of childless 37 to 39-year-old women ranges from $1.8 \%$ to $3.2 \%$ (ACS and CPS respectively). ${ }^{24}$ In both cases the effect of the Great Recession is not very large, and confidence intervals are quite wide, especially in the CPS smaller sample, where, even though positive, the lower bound is close to zero (i.e. 0.003 in models (1)-(2) in Table 4).

Our focus on 37-39 year old women follows the rationale of trying to quantify the persistent effect of the crisis on fertility, focusing on women close to the end of their reproductive life for whom a postponed birth likely means a lost child due to the biological difficulties in conceiving after the age of 40. In this respect it is important to stress that first birth rates of women 40-44 have been stable at about 2.2 and 2.3 births per 1000 women of that age (CDC/NCHS) between 2008 and 2013. This means that if women around 37-39 had postponed childbearing during the crisis of 2007-2009, as we have shown in this paper, there is no evidence that those postponed births would have been recuperated after 2010 .

We have also replicated the analysis varying the age range. We show that this crisisrelated effect of increasing childlessness rates is larger among women in their early thirties. However, as already mentioned, women in their early-to-mid thirties could still recuperate the postponed births after the end of the Great Recession, while this seems very unlikely for women close to their forties.

Rising rates of childlessness have implications both for societies and individual lives. First, childlessness has demographic implications like declining birth rates and population decline and ageing. Second, these changes in the population structure have economic implications, such as the increase in the dependency ratio (the proportion of retirees to working age population), which burden public spending and generate intergenerational imbalances in the distribution of economic resources (e.g. spending in the elderly health care system versus spending in education and social benefits). At the individual level, there is no evidence of any health-related or emotional cost of 
childlessness, even though the case of women who remain childless because of postponing motherhood is seldom treated. Nonetheless, childless old individuals, especially if in poor health, have been shown to be sensibly more likely to be in social isolation (Koropeckyj-Cox and Vaughn 2007; Connidis 2010) and in institutionalization (Rowland 1998).

In the paper we also touch upon some possible mechanisms through which the crisis might affect fertility and, in our specific case, childlessness. In the analysis we control for education, marital status and state level unemployment rates. Considering that we are focusing on women at about the age of forty, their educational level is very likely exogenous to the model and a pure control variable. In fact, there is no evidence of a mediating effect of education at 37-39 years old, unlike the marital status case. The economic crisis puts a strain on marriages, both in terms of the likelihood of new marriages and the surviving of existing ones. If marriages as less frequent due to the recession, births are also less likely. This is clearly evident from our findings, as adding marital status to the model halves the main period effect (e.g. Model (4) in Table 2): married women with a present spouse in our treatment group are far less likely to stay childless because of the recession, while single 37 to 39-year-old women are the ones with the highest risk.

Rising unemployment rates, instead, do not appear as major factors in deciding whether a woman remains childless in her late thirties (see Table 7). In line with previous studies (Currie and Schwandt 2014), we only find an effect of unemployment rates on childless young women, particularly in the age range 20-24. Dehejia and Lleras-Muney (2004) also find that in the US the fertility response to rising unemployment differs substantially by ethnicity and socioeconomic status: for instance, the negative effect of an increase in the unemployment rate is twice as much for Blacks compared to Whites.

As a final remark we want to mention that the research design that we have used in this paper could be usefully further extended to study childlessness rates in the European countries, using for instance the Labor Force Survey Data. Our identification strategy based on a 'treatment at a specific age with pseudo cohorts' could be applied to study other outcomes, like higher parities, for instance, the proportion of couples with 2 or 3 children, or to study other treatments like past recessions or policy interventions that create incentives or disincentives for childbearing.

\section{Endnotes}

${ }^{1}$ We follow the official declaration of the business cycle dating committee of the US National Bureau of Economic Research (NBER) that the Great Recession in the US began in December 2007 and ended in June 2009. Therefore we take 2007 as the last non-recession year and 2009 as the last recession year (as done for instance in Starr 2014), and, as usually done in the literature, we measure childlessness with a one-year delay in 2010.

${ }^{2}$ We also conducted in-depth descriptive comparisons of the treatment and control cohorts to check whether this assumption is correct, and we repeated the analysis varying the age range of the cohorts as a further robustness check of our findings. See the next sections for details.

${ }^{3}$ As a further robustness check we also varied the age range (20-24; $\left.25-29 ; 30-34\right)$ and the age bandwidth $(36-40 ; 36-41 ; 37-40)$. 
${ }^{4}$ For a recent debate on the application of causal inference designs in population studies see: Bhrolcháin and Dyson 2007; Duncan et al. 2007; Engelhardt, Kohler, and FürnkranzPrskawetz 2009; Fricke 2003; Hoem 2010; Moffitt 2003, 2005; Neyer and Andersson 2008; Russo and Williamson 2011; Smith 2009, 2014; Xie 2007, 2013.

${ }^{5}$ In a different context, Dinas and Stoker (2014) define a similar design as 'at a single point in the life cycle'.

${ }^{6}$ Examples of recent empirical applications of the pseudo-panel method are: Russell and Fraas (2005); Verbeek (2008); Azevedo and Robles (2010); Bernard, Bolduca, and Yameogob (2011); Barufi (2012) and Chi-Hong Tsai et al. (2014).

${ }^{7}$ I excluded from the sample women living in Group Quarters, meaning institutions for two reasons, first, because they represent a very special case and, second, because they are excluded from the ACS survey waves 2000-2005.

${ }^{8}$ US National Bureau of Economic Research (NBER).

${ }^{9}$ Groups are, in fact, pseudo birth cohorts.

${ }^{10}$ State fixed effect, educational attainment, marital status and employment status.

${ }^{11}$ We support this claim with descriptive evidence in the following Results section.

${ }^{12}$ Data available at http://www.cdc.gov/nchs/data/databriefs/db152.htm.

${ }^{13}$ From geographic areas with population larger than 65,000 . For less populated areas the sample must be accumulated over a number of years. The Census Bureau produces 3 -year estimates for areas with 20,000 individuals or more, and 5-year estimates for all geographic areas.

${ }^{14}$ Sample sizes are significantly smaller before 2004 because the ACS survey's size increased over time: in 2000 it was only of 1/750 of the US population, then between 2001 and 2004 it was around $0.4 \%$ of the population, and only since 2005 it is of $1 \%$.

${ }^{15}$ It does not include however women's stepchildren, because the question asks about own children only.

${ }^{16}$ Data and graphs not shown but available upon request.

${ }^{17} \mathrm{~A}$ descriptive graphical comparison, between ACS and CPS, of childlessness trends of various cohorts of white women (born between 1964 and 1975) has been conducted (figures not shown but available upon request). The two trends do not fit perfectly (the difference is roughly around 5\%) but they are parallel. We can attribute the systematic difference between the two samples to women who had children in the ACS sample but who do not live in the same residential unit as them. Since we are dealing with differences, it does not matter if the proportion is not exactly the same, as long as the distance between the two is systematically the same in all waves, as it appears to be.

${ }^{18}$ The first time the ACS was conducted was in 2000 , and we do not have data on the placebo group before they were 34-36.

${ }^{19}$ Figures regarding summary statistics and the distribution of variables across treatment and control (also for placebo) groups are available upon request.

${ }^{20}$ Employment status is not available for the June CPS, while education does not affect the estimate, as it was in the ACS case.

${ }^{21}$ The results on the second placebo treatment are the same. They are not reported but are available upon request.

${ }^{22}$ See Additional file 1: TableS1.

${ }^{23}$ See Additional file 1: Table S2. 
${ }^{24}$ As mentioned, this sizable difference between the two samples could be explained by the way the different questionnaires are conducted. If this is the case, the true effect is that of the CPS, where the key question is on the number of children ever had, and the difference of the DD estimate with the ACS (where the question in on the number of children residing in the household) is due to more families keeping the children at home due to the recession, a factor decreasing the difference in the treatment group and reducing the ACS point estimate.

\section{Additional file}

Additional file 1: Table S1. Complementary analysis on the effect of State Unemployment rate on childlessness (ACS). Robustness check varying the bandwidth. Table S2. Complementary analysis on the effect of State Unemployment rate on childlessness (ACS). Robustness check for different age groups. (DOC $137 \mathrm{~kb}$ )

\section{Competing interests}

The IZA Journal of Labor Economics is committed to the IZA Guiding Principles of Research Integrity. The authors declare that they have observed these principles.

\section{Acknowledgments}

The research leading to these results has received funding from the European Union's Seventh Framework Programme (FP7/2007-2013) under grant agreement no. 320116 for the research project Families and Societies. We would also like to thank Elias Dinas, Gabriel Facchini Palma and the participants to the Inequality Working group of the European University Institute for the valuable suggestions on earlier drafts of the paper. We also thank the anonymous referees and the editor for the useful remarks.

Responsible editor: Pierre Cahuc

Received: 21 July 2015 Accepted: 29 October 2015

Published online: 13 November 2015

\section{References}

Adsera A (2004) Changing fertility rates in developed countries. The impact of labor market institutions. J Popul Econ 17:17-43

Adsera A (2011) The interplay of employment uncertainty and education in explaining second births in Europe. Demogr Res 25(16):513-544

Ahlburg DA (1983) Good times, bad times: a study of the future path of U. S. fertility. Soc Biol 30(1):17-23

Azevedo, V. and M. Robles (2010) Geographical Poverty Traps in Ecuador Using Pseudo Panel Data. Paper presented at the 2010 PAA Conference

Barufi AM (2012) Income inequality reduction in Brazil: a pseudo-panel approach in the search of its determinants. TD Nereus 11. San Paolo, Brazil

Baudin T, De La Croix D, Gobbi P (2015) Fertility and childlessness in the United States. Am Econ Rev 105(6):1852-1882

Becker GS (1960) An Economic Analysis of Fertility. Demographic and Economic Change in Developed Countries, a Conference of the Universities - National Bureau Committee for Economic Research. Princeton University Press, Princeton, NJ

Bernard J, Bolduca D, Yameogob ND (2011) A pseudo-panel data model of household electricity demand. Resour Energy Econ 33:315-25

Bhrolcháin MN, Dyson T (2007) On causation in demography: issues and illustrations. Popul Dev Rev 33(1):1-36

Butz W, Ward M (1979) The emergence of countercyclical U.S. fertility. Am Econ Rev 69(3):318-28

Collado MD (1997) Estimating dynamic models from time series of independent cross-sections. J Econ 82:37-62

Connidis, IA (2010) Family ties and aging. Pine Forge Press

Currie J, Schwandt H (2014) Short- and long-term effects of unemployment on fertility. Proc Natl Acad Sci 111(41):14734-14739

Deaton A (1985) Panel data from time series of cross-sections. J Econ 30:109-26

Dehejia, R.H. and Lleras-Muney A (2004) Booms, Busts, and Babies' Health. The Quarterly Journal of Economics 119 (3), 1091

Del Bono E, Weber A, Winter-Ebmer R (2014) Fertility and economic instability: the role of unemployment and job displacement. J Popul Econ 28(2):463-78

Dinas E, Stoker L (2014) Age-period-cohort analysis: a design-based approach. Elect Stud 33:28-40

Duncan, G., F. Gardes, P. Gaubert, and C. Strarzec (2007) Panel and Pseudo-Panel Estimation of Cross- Sectional and Time Series Elasticities of Food Consumption: The Case of American and Polish Data edited by Institut National De La Statistique Et Des Etudes Economiques Série des Documents de Travail du CREST (Centre de Recherche en Economie et Statistique)

Engelhardt H, Kohler H-P, Fürnkranz-Prskawetz A (2009) Causal analysis in population studies. Springer Netherlands, Dordrecht

Ermisch J-F (1980) Time costs, aspirations and the effect of economic growth on German fertility. Oxf Bull Econ Stat 42(2):125-143 
Ermisch J (1988a) Econometric analysis of birth rate dynamics in Britain. J Hum Resour 23(4):563-576

Ermisch J (1988b) Economic influences on birth rates. Natl Inst Econ Rev 126:71-81

Firebaugh G (2008) Seven rules for social research. Princeton University Press, Princeton

Fokkema T, de Valk H, de Beer J, van Duin C (2008) The Netherlands: childbearing within the context of a 'Poldermodel' Society. Demogr Res 19(21):743-94

Fricke T (2003) Culture and causality: an anthropological comment. Popul Dev Rev 29(3):470-79

Giersbergen NPA, de Beer J (1997) Birthrate and consumer trust: an econometric analysis. Maandstatistiek van de bevolking., pp 23-27

Goldstein JR, Kreyenfeld M, Jasilioniene A, Orsal DK (2013) Fertility reactions to the 'Great Recession' in Europe: recent evidence from order-specific data. Demogr Res 29(4):85-104

Hoem JM (2010) Causal analysis in population studies: concepts, methods, applications by H. Engelhardt; H-P. Kohier; A. Prskawetz. Eur J Popul 26(4):507-9

Inanc $\mathrm{H}$ (2015) Unemployment and the timing of parenthood: implications of partnership status and partner's employment. Demogr Res 32(7):219-250

Koropeckyj-Cox T, Vaughn RAC (2007) Characteristics of older childless persons and parents cross-national comparisons. J Fam Issues 28(10):1362-1414

Kreyenfeld M, Andersson G (2014) Socioeconomic differences in the unemployment and fertility Nexus: evidence from Denmark and Germany. Adv Life Course Res 21:59-73

Lee $R$ (1990) The demographic response to economic crisis in historical and contemporary populations. Popul Bull UN 29:1-15

Lesthaeghe RJ (2010) The Unfolding Story of the Second Demographic Transition. PSC Research Report No. 10-696 Macunovich DJ (1996) Relative income and the price of time: exploring their effects on US fertility and female labor force participation. Popul Dev Rev 22:223-57

Macunovich DJ (1995) The Butz-Ward fertility model in the light of more recent data. J Hum Resour 30(2):229-55

McDonald P (2000) The 'Toolbox' of Public Policies to Impact on Fertility - a Global View, Edited by European Observatory on Family Matters

McKenzie DJ (2003) How do households cope with aggregate shocks? Evidence from the Mexican peso crisis. World Dev 31(7):1179-99

McKenzie DJ (2004) Asymptotic theory for heterogeneous dynamic pseudo-panels. J Econ 120:235-262

Meron M, Widmer I (2002) Unemployment leads women to postpone the birth of their first child. Popul Engl Ed 57(2):301-30

Moffitt R (1993) Identification and estimation of dynamic models with a time series of repeated cross-sections. J Econ 59:99-123

Moffitt R (2003) Causal analysis in population research: an Economist's perspective. Popul Dev Rev 29(3):448-58 Moffitt R (2005) Remarks on the analysis of causal relationships in population research. Demography 42(1):91-108

Morgan, S. P., E. Cumberworth, and C. Wimer (2011) The Partisan (Red/Blue) Fertility Response to the Great Recession. Paper presented at the 2011 PAA Conference

Morgan SP, Cumberworth E, Wimer C (2012) Sheltering the Storm: American Families in the Great Recession. Pathways Mynarska M, Matysiak A, Rybińska A, Valentina T, Vignoli D (2015) Diverse Paths into Childlessness over the Life Course. Advances in Life Course Research 23:35-48

Naz G (2004) The impact of cash-benefit reform on parents? Labour force participation. J Popul Econ 17(2):369-83

Naz G (2010) Effect of a family policy reform on immigrants' labour supply and earnings. Labor 24(1):74-92

Neyer $\mathrm{G}$, Andersson G (2008) Consequences of family policies on childbearing behavior: effects or artifacts? Popul Dev Rev 34(4):699-724

Rindfuss RR, Morgan SP, Swicegood G (1988) First Births in America. University of California Press, Berkeley

Rowland DT. (1998) Consequences of childlessness in later life. Australian Journal on Ageing 17(1):24-28.

Russell JE, Fraas JW (2005) An application of panel regression to pseudo panel data. Multiple Linear Regression Viewpoints 31(1):1-15

Russo F, Williamson J (2011) Generic versus single-case causality: the case of autopsy. Eur J Philos Sci 1(1):47-69

Silver M (1965) Births, marriages, and business cycles in the United States. J Polit Econ 73(3):237-255

Smith HL (2014) Effects of causes and causes of effects some remarks from the sociological side. Sociol Methods Res 43(3):406-415

Smith HL (2009) Causation and its discontents. In: Engelhardt H, Kohler H-P, Fürnkranz-Prskawetz A (eds) Causal analysis in population studies, the springer series on demographic methods and population analysis. Springer, Netherlands, pp 233-42

Sobotka T, Skirbekk V, Philipov D (2011) Economic recession and fertility in the developed world. Popul Dev Rev 37(2):267-306

Sobotka T, Skirbekk V, Philipov D (2010) Economic recession and fertility in the developed world. A literature review. Popul Dev Rev 37(2):267-306

Starr MA (2014) Gender, added-worker effects, and the 2007-09 recession: looking within the household. Rev Econ Househ 12(2):209-235

Tsai C-H, Mulley C, Clifton G (2014) A review of pseudo panel data approach in estimating short-run and long-run public transport demand elasticities. Transp Rev 34(1):102-121

Verbeek M, Vella F (2005) Estimating dynamic models from repeated cross-sections. J Econ 127:83-102

Verbeek M (2008) Pseudo panels and repeated cross-sections. In: Màtyàs L, Sevestre P (eds) The econometrics of panel data: fundamentals and recent developments in theory and practice. RSM Erasmus University and Netspar. Springer, The Netherlands

Xie Y (2013) Population heterogeneity and causal inference. Proc Natl Acad Sci 110(16):62-68

Xie Y (2007) Otis Dudley Duncan's legacy: the demographic approach to quantitative reasoning in social science. Research in Social Stratification and Mobility 25(2):141-56 